\title{
Elongation, rooting and acclimatization of micropropagated shoots from mature material of hybrid larch
}

\author{
Nicole Brassard ${ }^{1}$, Line Brissette ${ }^{2}$, Daniel Lord ${ }^{2} \&$ Sylvie Laliberté ${ }^{1}$ \\ ${ }^{1}$ Gref, Université du Québec À Montréal, Département des Sciences Biologiques, C.P. 8888, Succ. Centre-Ville, \\ Montréal, Québec, Canada H3C $3 P 8 ;{ }^{2}$ Université du Québec ả Chicoutimi, Département des Sciences \\ Fondamentales, 555 Boulevard de l'Université, Chicoutimi, Québec, Canada G7H 2BI
}

Received 20 September 1994; accepted in revised form 12 September 1995

Key words: acclimatization, conifer, Larix $\times$ eurolepis, mature material, plagiotropism, rooting, stem elongation

\begin{abstract}
Factors were defined for elongation, rooting and acclimatization of micropropagated shoots of Larix $\times$ eurolepis Henry initiated from short shoot buds of plagiotropic stecklings serially propagated for 9 years from an 8-year-old tree. Initiation and multiplication were on Schenk and Hildebrandt (SH) medium supplemented with $5 \mu \mathrm{M} 6-$ benzyladenine (BA) and $1 \mu \mathrm{M}$ indole-butyric acid (IBA). Stem elongation was obtained in $36 \%$ of the shoots on SH medium containing $0.5 \mu \mathrm{M} \mathrm{BA}$ and $63 \%$ of the remaining non-elongated shoots initiated stem elongation after transfer on SH medium devoid of growth regulators. Rooting involved 2 steps: root induction on Campbell and Durzan mineral salts and Murashige and Skoog organic elements, both half-strength (CD-MS/2), supplemented with $1 \mu \mathrm{M}$ of both naphthaleneacetic acid (NAA) and IBA, and root elongation following transfer to CD-MS/2 medium devoid of growth regulators. Repeating this 2 -step sequence yielded up to $67 \%$ rooted shoots. Acclimatization of plantlets ranged from $83 \%$ to $100 \%$. Over 300 plants were transferred to the greenhouse; some showed plagiotropic growth.
\end{abstract}

\section{Introduction}

Micropropagation of mature trees is important in refor estation since it allows multiplication of superior genotypes whose characteristics have been evaluated in the field. Breeding programs achieve genetic gains for desired traits due to additive genetic variation, but non-additive variation, which can exceed $50 \%$ of the total genetic variability, can only be exploited through cloning mature ortets (Hasnain \& Cheliak, 1986). Further, cloning elite trees can increase genetic gain per unit time (Cheliak \& Rogers, 1990).

In conifers, in vitro regeneration was successful mostly from embryos or young seedlings (Bonga, 1991). Lack of elongation, rooting and orthotropic growth are often pitfalls in regenerating older trees. Maturation, a complex phenomenon, is the major problem preventing a wider application of tissue culture technology among woody species (Pierik, 1990). Despite this, shoot formation and elongation, using explants from mature conifers, have been reported in Thuja (Coleman \& Thorpe, 1977), Pinus (Gupta \& Durzan, 1985; Abdullah et al., 1987) and Picea (Mac An t-Saoir et al., 1991). However, rooting, acclimatization and successful field trials are restricted to a few species including: Sequoia sempervirens (Boulay, 1987), Pinus radiata (Horgan \& Holland, 1989), Pinus pinaster (Monteuuis \& Dumas, 1992) and Pseudotsuga menziesii (Pullman \& Timmis, 1992).

With larch, Chesick et al. (1990) reported formation and elongation of multiple buds in explants from a 20 -year-old Larix occidentalis tree, but rooting was not achieved. With $L$. decidua adventitious shoots were obtained from 19-year-old trees, rooting ranged from $53 \%$ to $81 \%$ (Diner, 1990) and 9 rooted plantlets were produced from 140-year-old trees (Kretzschmar \& Ewald, 1994). Adventitious shoot formation from cultures of 30-year- old trees of $L$. decidua, L. leptolepis and the hybrid, $L . \times$ eurolepis was reported by Bonga \& Pond (1991) and Bonga \& von Aderkas 
(1988) with limited elongation and rooting success. No plant survived transfer to soil. With the same hybrid, Laliberté \& Lalonde (1988) established a subculturable organogenic callus system from mature material and produced 14 rooted plants.

Hybrid larch, with its rapid growth rate, good wood properties and canker resistance is excellent for reforestation (Pâques, 1989). Unfortunately, the genus suffers from poor seed set and irregular yields (New Brunswick Forest Research Advisory Committee, 1986). In this paper, we report experiments performed with organogenic cultures established from mature material of $L$. $\times$ eurolepis : plagiotropic stecklings that were serially propagated for 9 years from an 8-year-old ortet. The goals of the study were to determine cultural and environmental factors for efficient stem elongation, rooting and acclimatization of the micropropagated shoots.

\section{Materials and methods}

\section{Plant material}

Organogenic cultures were initiated from vegetative short shoot buds of clone 976 of Larix $\times$ eurolepis following the procedure of Laliberte \& Lalonde (1988). Branches were collected from plagiotropic stecklings (rooted cuttings) that had been established in 1981 from an ortet sown in 1973 and that had been serially propagated by rooting of cuttings every 2 to 3 years since 1981. The ortet that provided the cuttings for the first set of stecklings was 8 years old at that date. They were stored for a few weeks in plastic bags at $4{ }^{\circ} \mathrm{C}$ until used to initiate cultures in January 1990.

\section{Surface disinfestation}

Non-lignified branch segments bearing two or three axillary buds were surface-disinfested in agitated solutions of $85 \%$ ethanol for $2 \mathrm{~min}$ followed by a $6 \%$ sodium hypochlorite solution (non-diluted commercial bleach) for $15 \mathrm{~min}$ and $70 \%$ ethanol for $2 \mathrm{~min}$. They were then rinsed three times in sterile deionized distilled water with agitation for 10-15 min each. Bud scales were removed and the apex excised in sterile distilled water.

\section{Media}

Culture initiation and shoot multiplication were performed on basal medium (M) consisting of Schenk \& Hildebrandt (SH) (1972) mineral salts and vitamins with the exception that the NaFeEDTA stock solution was prepared according to Steiner \& Van Winden (1970). For stem elongation and rooting, SH and DCR (Gupta \& Durzan, 1985) media were used either at full or half-strength (SH/2, DCR/2), with or without $0.3 \%(\mathrm{w} / \mathrm{v})$ neutralized activated charcoal (SIGMA no. C5385) (AC). For rooting, mineral salts of Campbell \& Durzan (1975) and organic supplements of Murashige \& Skoog (1962), both at half-strength, were also used (CD-MS/2). All media contained 0.7\% (w/v) Difco Bacto-agar and 3\% (w/v) sucrose. Plant growth regulators were added, the $\mathrm{pH}$ was adjusted to 5.7 and 15 $\mathrm{ml}$ of medium was dispensed to each $20 \times 150 \mathrm{~mm}$ test tube, closed with Kimble Kim-Kaps no. 73660 prior to autoclaving at $103.3 \mathrm{kPa}$ and $121^{\circ} \mathrm{C}$ for $15 \mathrm{~min}$.

\section{Culture procedure}

\section{Initiation and shoot multiplication}

Culture initiation and shoot multiplication were carried out on SH basal medium supplemented with $1 \mu \mathrm{M}$ IBA and $5 \mu \mathrm{M}$ BA (M). At each subculture (every 46 weeks) shoot clumps were fragmented, dark brown callus tissue was discarded and small clumps of shoots were retained on multiplication medium.

\section{Stem elongation}

The cultures had been on multiplication medium for 33 weeks and were at their sixth subculture at the start of the elongation experiments. Shoots had no visible elongated stems at this stage and only those with welldeveloped needles were selected. The stem elongation process involved two steps. First, the shoots were cultured on SH medium containing various concentrations of BA and IBA. Shoots with stems $>5 \mathrm{~mm}$ were considered elongated and used for rooting, whereas shoots with non-elongated stems from SE1 ( $\mathrm{SH}$ medium plus $0.5 \mu \mathrm{M} \mathrm{BA}$ ) were given second elongation treatments on SH and DCR media containing various concentrations of BA and IBA. Media showing best results for first and second stem elongation treatments were identified as SE1 and SE2 (SH medium without growth regulators), respectively.

At least 20 shoots were tested for each medium of both treatments. Experiments were repeated twice. 
Shoots with elongated stems were counted at the end of the subculture period ( 6 weeks). The complete multiplication and stem elongation process thus involved a sequence of three media: M-SE1-SE2. The experiments were performed over a 2-year period and the selected SE1-SE2 sequence was repeated six times starting each time with at least 100 shoots from the multiplication medium.

\section{Rooting}

When present, basal callus was excised prior to root induction treatments; 52 shoots with elongated stems (>5 mm) were distributed equally in SH/2 and CDMS/ 2 media containing $1 \mu \mathrm{M}$ IBA and $1 \mu \mathrm{M}$ NAA and kept under an 8-h photoperiod in a growth chamber. After 14 to 28 days, the shoots were subcultured in the same medium devoid of growth regulators for root elongation.

The following rooting experiments were performed in a different laboratory; shoots were sent in test tubes sealed with Parafilm and were in the dark for ca $48 \mathrm{~h}$ during transportation. The shoots were first separated according to their previous stem elongation medium and further classified into three stem length classes: 5 to $10 \mathrm{~mm}, 10$ to $30 \mathrm{~mm}$ and 30 to $80 \mathrm{~mm}(48,47$ and 45 shoots from SE1 and 23, 16 and 27 shoots from SE2, respectively). They were distributed in the root induction medium (RI) CD-MS/2 supplemented with $1 \mu \mathrm{M}$ IBA and $1 \mu \mathrm{M}$ NAA for 18 to 32 days, and then transferred to root elongation (RE) medium CD-MS/2 devoid of growth regultors for about 4 weeks. The RIRE sequence was repeated with 40 additional shoots in the $30-80 \mathrm{~mm}$ stem length class and after 59 days the shoots without root formation were given a second RI-RE treatment. As root primordia emerged, cultures were transferred to a growth chamber under high pressure sodium lamps. The shoots with red-tipped root primordia were counted weekly. The number of rooted plantlets was recorded after 83 days. Only plantlets with elongated roots $(20-40 \mathrm{~mm})$ suitable for acclimatization were considered rooted.

\section{Acclimatization}

Rooted plantlets were removed from tubes and their roots washed under tap water. They were then potted in indivdual. $5 \times 6 \times 6 \mathrm{~cm}$ plastic pots containing a mixture of peat moss and perlite $(3: 1)$. To provide a high degree of humidity, each pot was covered with an inverted Magenta box (SIGMA GA Vessel) for 2 to 5 weeks and kept in a growth chamber under the same conditions as for root elongation. The plantlets were then transferred to a greenhouse and 20 of them were subsequently transferred to the field.

\section{Culture conditions}

For culture initiation, shoot multiplication and stem elongation, cultures were maintained in a temperaturecontrolled room at $28 \pm 1.5^{\circ} \mathrm{C}$ (test tube level) with a 16-h photoperiod ( $40 \mathrm{~W}$ Vita Lite fluorescent tubes, $55 \mu \mathrm{mol} \mathrm{m} \mathrm{m}^{-2} \mathrm{~s}^{-1}$ photosynthetically active radiation (PAR)). Root induction experiments took place in a growth chamber or temperature-controlled room. Both were at $23^{\circ} \mathrm{C}$, with an 8 -h photoperiod $(40 \mathrm{~W}$ Vita Lite fluorescent tubes, $55 \mu \mathrm{mol} \mathrm{m}{ }^{-2} \mathrm{~s}^{-1}$ PAR). For root elongation and acclimatization cultures were transferred to a growth chamber under high pressure sodium lamps providing $150-200 \mu \mathrm{mol} \mathrm{m}^{-2} \mathrm{~s}^{-1}$ PAR for a 16-h photoperiod and a day/night temperature of $23 / 17$ ${ }^{\circ} \mathrm{C}$.

\section{Statistical analyses}

As a first step, chi-square tests were used to assess differences among replicates within each treatment. The results of each replicate within a treatment were then combined to assess differences between treatments. Chi-square tests were computed using the Statistical Analysis System (SAS Proc GLM, SAS Institute Inc., 1987) software. The chi-square component of Pearson was computed to define the significant deviations between observed and expected values for each cell in all the chi-square tables (Bishop et al., 1975; Legendre \& Legendre, 1984). Raw frequency data were used to compute all chi-square tests. However, graphs are expressed in percentages since this illustrates the results with greater clarity.

\section{Results}

\section{Stem elongation}

The shoot clumps showed no visible elongated stems in multiplication stage and had to undergo a stem elongation process that involved a two-step sequence. Several stems elongated more than $5 \mathrm{~mm}$ in the first series of treatments, when transferred directly from the multiplication medium (M), to $\mathrm{SH}$ medium containing various concentrations of plant growth regulators (Fig. 1). Use of media containing IBA and BA resulted in low 


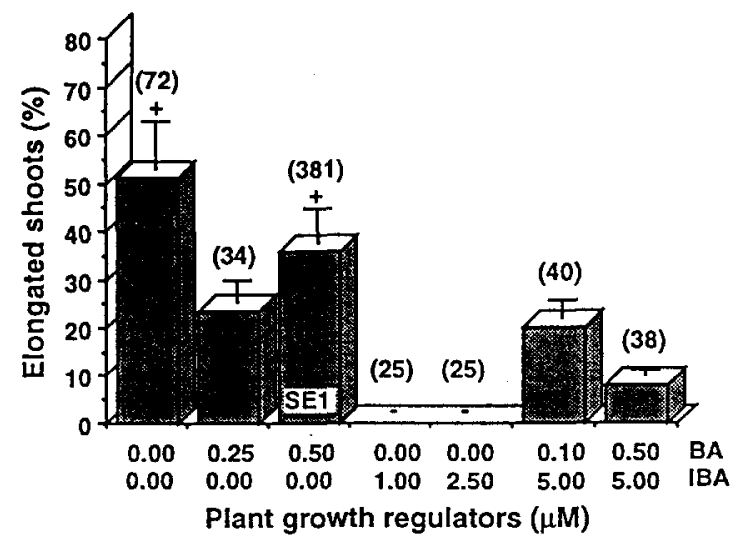

Fig. I. Percentage of shoots elongating in $\mathrm{SH}$ medium in the first stem elongation treatment directly after the multiplication stage. Raw frequency data were used to compute chi-square tests. Total number of shoots on which the percentages are based appear in parentheses. SE1: selected first stem elongation medium (SH containing $0.5 \mu \mathrm{M}$ BA). + and - indicate that values are significartly $(p<0.05)$ higher or lower respectively than the expected value given by the Pearson chi-square components.

percentages of stem elongating with no elongation at all when IBA was present alone. The best percentage (51\%) occurred on SH medium without growth regulators. But, because the stems were thin and the leaves pale green, these shoots were not considered suitable for subsequent rooting experiments. On $\mathrm{SH}$ medium containing $0.5 \mu \mathrm{M} \mathrm{BA}, 36 \%$ of the shoots showed stem elongation and green healthy needles suitable for rooting; this medium was selected as the best first stem elongation treatment (SEl). Chi-square analysis revealed that $\mathrm{SH}$ medium with either 0 or $0.5 \mu \mathrm{M}$ BA without IBA both produced a significantly $(p<0.05)$ higher percentage of elongated shoots than the other treatments (Fig. 1).

During the second series of elongation treatments, performed on non-elongated shoots from SE1 medium, $22 \%$ to $63 \%$ of the stems elongated on $\mathrm{SH}$ and DCR media containing various growth regulators (Fig. 2). The SH medium containing $5 \mu \mathrm{M}$ IBA and either $0.1 \mu \mathrm{M}$ or $0.5 \mu \mathrm{M}$ BA supported a higher percentage of shoot elongating, $44 \%$ and $35 \%$ respectively, than during the first trial $(7 \%$ and $20 \%$, Fig. 1), while on medium containing $\mathrm{BA}$ as a sole growth regulator the percentage of elongated shoots was similar in the two trials. On DCR medium wih $5 \mu \mathrm{M}$ IBA and $0.1 \mu \mathrm{MBA}$, $20 \%$ of the shoots elongated. Adding activated charcoal or halving the concentration of $\mathrm{SH}$ medium did not significantly $(p>0.05)$ increase the number of elongated shoots. However, activated charcoal added to both

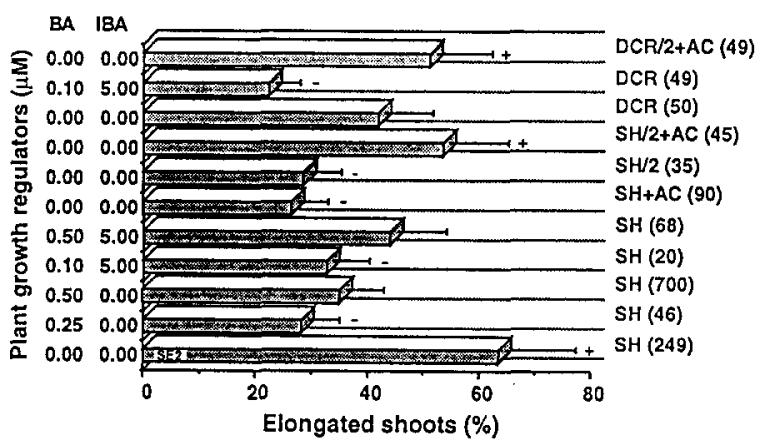

Fig. 2. Percentage of shoots elongating in SH and DCR media in the second stem elongation treatment performed on non-elongated shoots from the SE1 medium. Raw frequency data were used to compute chi-square tests. Total number of shoots on which the percentages are based appear in parentheses. SE2: selected second elongation medium (SH without plant growth regulators). AC: activated charcoal. + and - indicate that values are significantly $(p<$ 0.05 ) higher or lower respectively than the expected value given by the Pearson chi-square components.

half-strength $\mathrm{SH}$ and DCR media without growth regulators resulted in significantly $(p<0.05)$ higher results. Three media, SH/2+AC, DCR/2+AC and SH without growth regulators, supported significantly $(p<0.05)$ higher frequencies of elongated stems than the other treatments. The best response occurred on SH medium without growth regulators on which $63 \%$ of the shoots elongated; this medium was selected as the best second stem elongation treatment (SE2). As a whole, the SE1 + SE2 series yielded a total of $75 \%$ elongated stems. The elongated shoots from this second series had thick stems and deep green needles and were well suited for rooting.

In both series of experiments, the stem elongation occurred during the fifth and sixth weeks after subculture. A longer period, i.e. over 7 weeks, or a second passage on SE2 medium, was harmful to the shoots, which then dried.

\section{Rooting and acclimatization}

Rooting involved a two-step (RI-RE) procedure: induction on a medium containing $1 \mu \mathrm{M}$ IBA and 1 $\mu \mathrm{M}$ NAA (RI) and elongation on the same medium devoid of growth regulators (RE).

Under 8-h and 16-h photoperiods for RI and RE respectively, on $\mathrm{SH} / 2$ medium, 14 shoots developed hypertrophied root primordia but fast callus growth inhibited further root elongation. On CD-MS/2 medi- 


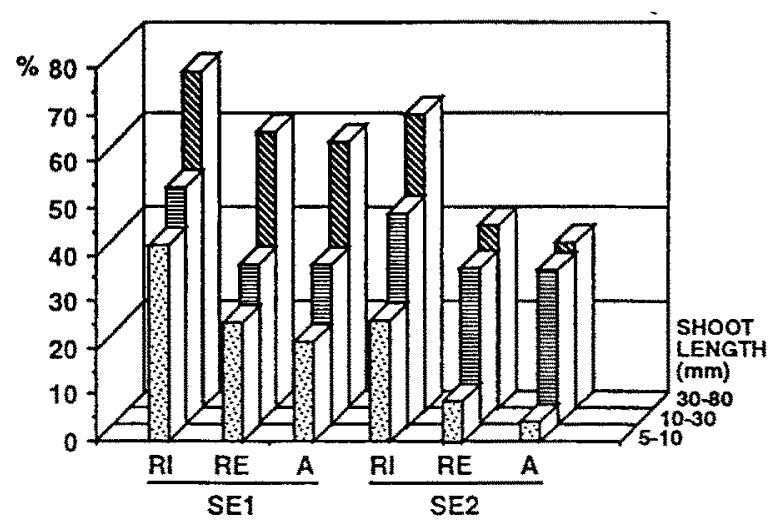

Fig. 3. Percentage of shoots with visible root primordia (RI) and root elongation (RE), and acclimatized plantlets (A) coming from $\mathrm{SE} 1$ or SE2 media in relation to initial shoot length. Raw frequency data were used to compute chi-square tests. See text for significance threshold.

um, callus growth was slow, 5 shoots developed root initials of which 4 showed root elongation.

After being submitted to a dark period of ca $48 \mathrm{~h}$ following stem elongation, shoots were put on CDMS/2 medium under 8-and 16-h photoperiods for RI and $\mathrm{RE}$ respectively. Best results were from the $30-80$ $\mathrm{mm}$ stem length class issued from the SE1 medium where $71 \%$ of the shoots developed red-tipped root primordia (Fig. 3). The best physical conditions for root induction were $23-24{ }^{\circ} \mathrm{C}, 8$-h photoperiod and 50 $\mu \mathrm{mol} \mathrm{m} \mathrm{m}^{-2} \mathrm{~s}^{-1}$ PAR. However, some primordia were formed at 16 -h photoperiod, provided that PAR was lower than $100 \mu \mathrm{mol} \mathrm{m}^{-2} \mathrm{~s}^{-1}$ (data not shown).

When transferred under high PAR and 16-h photoperiod, between $33 \%$ and $82 \%$ of the shoots with root primordia showed root elongation (Figs 3,4). Not all root primordia elongated because callus growth sometimes engulfed the shoot base and inhibited root growth. Many shoots had their lower needles dried during the root elongation period but apical buds produced healthy growth. However, if shoots were transferred before emergence of root primordia, all needles dried and were shed. When a second RI-RE treatment was applied to remaining non-rooted shoots of the 30-80 $\mathrm{mm}$ stem length class, $17 \%$ more rooted.

The stem elongation media (SE1 or SE2) did not significantly $(p>0.05)$ affect the number of shoots with visible root primordia.However, root elongation and plantlet acclimatization results were significantly $(p<0.05)$ different: the shoots from SE1 rooted and were acclimatized more easily than those from SE2.

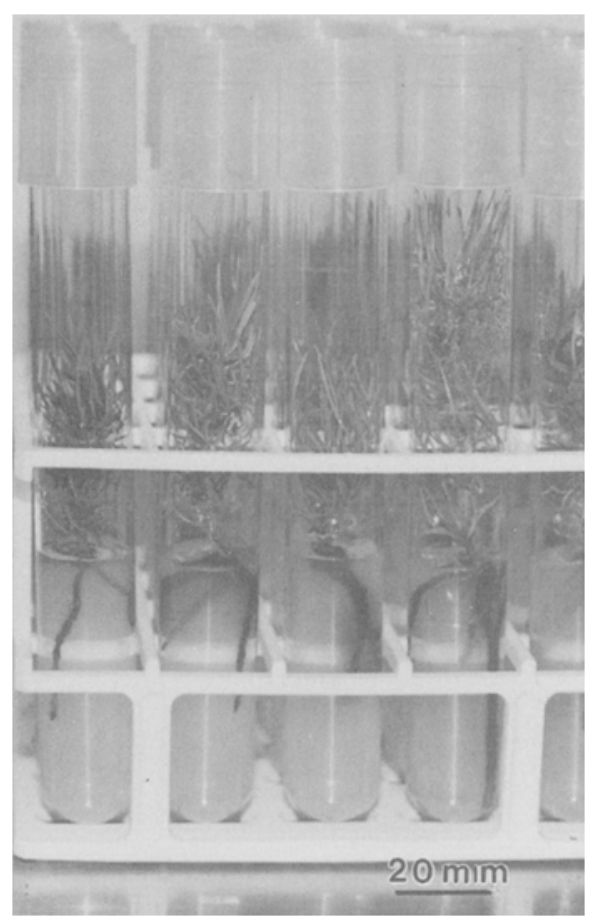

Fig. 4. In vitro plantlets with elongated roots suitable for acclimatization.

Stem length at the beginning of the experiments had a very significant $(p<0.001)$ influence on the number of shoots with visible root primordia, on root elongation and on plantlet acclimatization. The shoots in the 30-80 $\mathrm{mm}$ stem length class rooted and were acclimatized in greater number than those in the $5-10 \mathrm{~mm}$ stem length class.

There was no significant $(p>0.05)$ difference between the number of rooted shoots and of acclimatized plantlets. All shoots in the $10-30 \mathrm{~mm}$ stem length class got acclimatized. Those from the $5-10 \mathrm{~mm}$ stem length class proved the most difficult to root and to acclimatize regardless of the shoot elongation treatment they received. Over 300 plants were transferred to the greenhouse (Fig. 5) some of which showed plagiotropic growth. Out of 20 plants subsequently transferred in the field, after 18 months, a plagiotropic one did not survive while 19 others showed orthotropic growth.

Preliminary tests indicated similar results for five other in vitro clones initiated from stecklings of the same age as the clone that was used for this study (data not shown). 


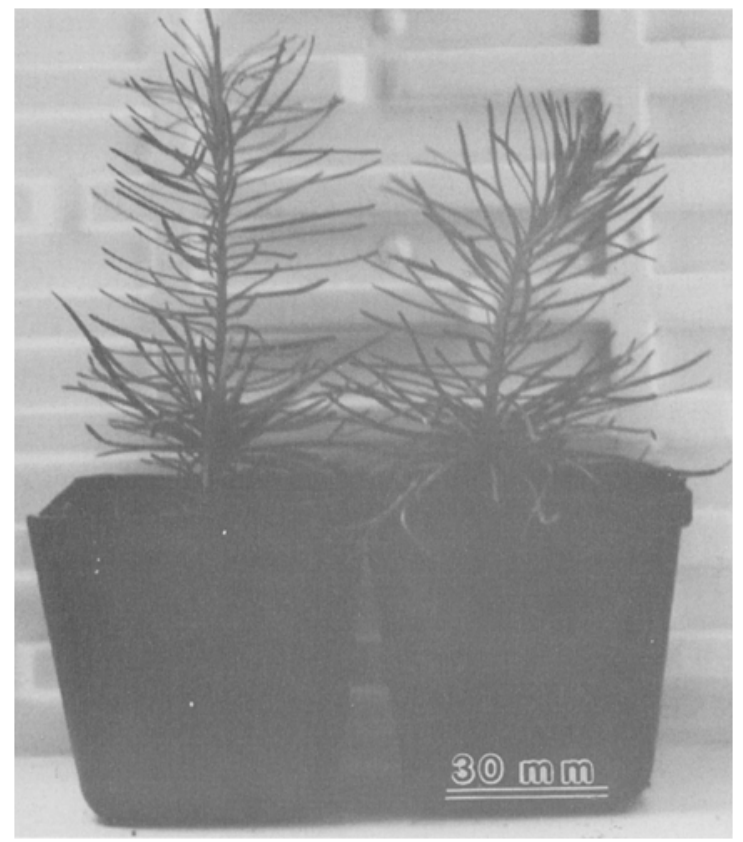

Fig. 5. Potted acclimatized plantlets.

\section{Discussion}

The present study was performed with well established, genetically stable (Wyman et al., 1992; Richard et al., 1995) shoot multiplication cultures that had gone through six subcultures ( 33 weeks). This length of time in culture on medium containing both a cytokinin and an auxin differs from the protocol followed for several species of larch, including $L . \times$ eurolepis, where the explants from mature trees were transferred to media devoid of growth regulators 3 to 8 weeks after initiation (Bonga \& Pond, 1991; Bonga \& von Aderkas, 1988; Chesick et al., 1990; Diner, 1990). In addition, our cultures were initiated from stecklings that had been serially propagated every 2-3 years for 9 years. Repeated subcultures on cytokinin-containing media (Boulay, 1987; Pierik, 1990) and serial rooting of cuttings (Bonga, 1987) are recognized rejuvenation or re-invigoration techniques. Nevertheless, the serially propagated stecklings used as explant donors in our study, were plagiotropic, a growth type related to the mature state (Franclet, 1980).

Reducing or eliminating BA content in the medium induced stem elongation. Cytokinins commonly stimulate shoot proliferation and inhibit their elongation; a primary medium can be used to stimulate bud multipli- cation and later, they can be transferred to a secondary medium with other combinations of plant growth regulators (Huetteman \& Preece, 1993). Elongation of short shoot buds from explants of 10-year-old Pinus brutia trees (Abdullah et al., 1987) and of adventitious buds from seedling explants of Picea abies (Ewald \& Süss, 1993) was also enhanced by reducing the concentration of cytokinin in the culture medium. In hybrid larch, a first and second passage on a medium containing $0.5 \mu \mathrm{M} \mathrm{BA}$ induced stem elongation in respectively $36 \%$ and $33 \%$ of the shoots. Since clonal material produced from one genotype (clone 976) was used for these experiments, the variability observed was not a genotypic effect. Presumably, the shoots submitted to the first stem elongation treatment differed in endogenous BA levels and an additional transfer on a medium reduced in cytokinin might have been necessary to counteract BA carry-over effects in some shoots. For unknown reasons, gradually reducing the BA concentration from $5 \mu \mathrm{M}$ in the multiplication medium to 0.5 $\mu \mathrm{M}$ in SE1 to none in SE2 insured a better shoot quality than complete removal of BA immediately after multiplication phase.

The conditions favoring rooting of micropropagated shoots from mature material are much more specific than for juvenile shoots (Horgan \& Holland, 1989). Elongated shoots rooted following a first treatment with NAA and IBA for root induction (RI), and a second one without growth regulators for root elongation (RE). Other conifers from either mature or juvenile sources also required two or more passages on different media to root (Bonga \& von Aderkas, 1992; Dunstan, 1988; Berthon et al., 1989).

Stem length significantly affected rooting. Although in vitro shoots of Larix species were rooted before as short shoots and elongation occurred after acclimatization (Bonga \& von Aderkas, 1988; Laliberté \& Lalonde, 1988), rooting and acclimatization are generally more successful with longer shoots. With $L$. decidua the shoots had to attain a length of $10 \mathrm{~mm}$ (Diner, 1990) and those of Pseudotsuga menziesii, a length of $30 \mathrm{~mm}$ before they would root (Mapes et $a l ., 1981$ ) with an initial height of $41-60 \mathrm{~mm}$ giving the best percentage of plantlet survival in the latter (Mohammed \& Vidaver, 1990).

Many shoots had their lower needles dried during the root elongation period; however, the apical buds produced healthy growth as observed on Pseudotsuga menziesii (Mohammed et al., 1989). These lower needles might serve as a nutrient reservoir to support new root extension, which would explain the importance of 
initial stem height on survival since taller shoots possess more needles to provide a larger nutrient reservoir (Mohammed \& Vidaver, 1991).

A dark period at the beginning of the rooting stage is often required for root formation and, generally, a reduction of light intensity favors adventitious root formation and promotes rooting of cuttings (Hansen, 1987). In our study, darkness before RI-RE treatments increased the percentage of rooted shoots as demonstrated by the difference in results obtained in otherwise similar conditions. A 48-h dark period followed by $55 \mu \mathrm{mol} \mathrm{m}^{-2} \mathrm{~s}^{-1}$ PAR for an 8-h photoperiod, and a constant temperature of $23-24^{\circ} \mathrm{C}$ promoted root induction while root elongation was accomplished under a high PR, a 16-h photoperiod and a night temperature of $17^{\circ} \mathrm{C}$. Higher temperatures favor root initiation by affecting carbohydrate translocation, thus increasing respiration and catabolism of starch, whereas lower temperatures favor root elongation. An increase in PAR some days or weeks before transplanting increases the chances of survival (Gaspar \& Coumans, 1987) and high PAR enhances the photosynthetic ability of rooted plantlets and hastens the acclimatization process by accelerating the development of new leaves (Grout \& Millam, 1985).

In our study, some plants exhibited plagiotropy after a few weeks in the greenhouse. We cannot ascertain yet whether this was due to improper lignification related to fast growth of unstaked plants, an inadequate root system development or only partial rejuvenation. During the first growing season, Kretzschmar (1993) staked micropropagated plantlets from short shoot buds of seedlings of Larix $\times$ eurolepis to overcome plagiotropic growth habit. Plagiotropy is not restricted to tissue-cultured plantlets from mature material; for example, it was also noted in plantlets derived from embryos of loblolly pine (McKeand, 1985) and cotyledons of Pseudotsuga menziesii but these became upright by the third season unlike rooted cuttings that remained plagiotropic (Ritchie \& Long, 1986). Similarly, in Sequoia sempervirens plantlets established from mature trees, plagiotropy was of short duration (Boulay, 1987). In our study, after 18 months in the field, one plant was plagiotropic and did not survive while 19 others showed orthotropic growth. Further studies will have to be performed to optimize the in vitro to ex vitro transition.

\section{Acknowledgements}

The authors thank Mr. Pierre Périnet (Ministère des Ressources Naturelles du Québec) who provided hybrid larch stecklings and Dr. Sylvie Gauthier who helped with the statistical analyses and commented on the manuscript. Suggestions and comments from anonymous reviewers are gratefully acknowledged. This research was funded by a grant from the ministère des Ressources naturelles du Quèbec to S.L. and a grant from the Programme FODAR of the Université du Quèbec to S.L. and D.L.

\section{References}

Abdullah AA, Yeoman 21 \& Grace J (1987) Micropropagation of mature Calabrian pine (Pinus brutia Ten.) from fascicular buds. Tree Physiol. 3: 123-136

Berthon J-Y, Maldiney R, Sotta B, Gaspar T \& Boyer N (1989) Endogeous levels of plant hormones during the course of adventitious rooting in cuttings of Sequoiadendron giganteum (Lind1.) in vitro. Biochem. Physiol. Pflanzen 184: 405-412

Bishop YMM, Fienberg SE \& Holland PW (1975) Discrete Multivariate Analysis: Theory and Practice. MIT Press, Cambridge, Mass. (557 p)

Bonga JM (1987) Clonal propagation of mature trees: problems and possible solutions. In: Bonga JM \& Durzan DJ (eds) Cell and Tissue Culture in Forestry, Vol 1 (pp 249-271) Martinus Nijhoff/Dr. W Junk Publs. The Hague

Bonga JM (1991) In vitro propagation of conifers: fidelity of the clonal offspring. In Ahuja MR (ed) Woody Plant Biotechnology (pp 13-21). Plenum Press, New York

Bonga JM \& Pond SE (1991) Adventitious shoot formation in cultures of 30-year-old L. decidua, L. leptolepis, L. eurolepis, and L. laricina trees. Plant Cell Tiss. Org. Cult. 26: 45-51

Bonga JM: \& von Aderkas P (1988) Attempts to micropropagate mature Larix decidua Mill. In: Ahuja MR (ed) Somatic Cell Genetics of Woody Plants (pp 155-168). Kluwer Academic Publs, Dordrecht

Bonga JM \& von Aderkas P (1992) In vitro Culture of Trees. Forestry Sciences, Vol 38 Kluwer Academic Publs, Boston, (236 p)

Boulay M (1987) Conifer micropropagation: applied research and commercial aspects. In: Bonga JM \& Durzan DJ (eds) Cell and Tissue Culture in Forestry, Vol 3 (pp 185-206). Martinus Nijhoff/Dr. W Junk Publs. The Hague

Campbell RA \& Durzan DJ (1975) Induction of multiple buds and needles in tissue cultures of Picea glauca. Can. J. Bot. 53: 16521657

Cheliak WM \& Rogers DL (1990) Integrating biotechnology into tree improvement programs. Can. J. For. Res. 20: 452-463

Chesick EE, Bilderback DE \& Blake GM (1990) In vitro multiple bud formation by 20 -year-old western larch buds and stems. Hort Science 25: 114-116

Coleman WK \& Thorpe TA (1977) In vitro culture of western red cedar (Thuja plicata Donn). 1. Plantlet formation. Bot. Gaz. 138: 298-304

Diner AM (1990) Clonal micropropagation of mature Larix. New Forests 4: 63-66 
Dunstan DI (1988) Prospects and progress in conifer biotechnology. Can. J. For. Res. 18: 1497-1506

Ewald D \& Süss R (1993) A system for repeatable formation of elongating adventitious buds in Norway spruce tissue cultures. Silvae Genet. 42: 169-175

Franclet A (1980) Rajeunissement et propagation végétative des ligneux. Ann. Rech. Sylv. AFOCEL 1980: 12-40

Gaspar T \& Coumans M (1987) Root formation, In: Bonga JM \& Durzan DJ (eds) Cell and Tissue Culture in Forestry, Vol 2, (pp 202-217). Martinus Nijhoff/Dr. W Junk Publs. The Hague

Grout BWW \& Millam S (1985) Photosynthetic development of micropropagated strawberry plantlets following transplanting. Ann. Bot. 55: 129-131

Gupta PK \& Durzan DJ (1985) Shoot multiplication from mature trees of Douglas-fir (Pseudotsuga menziesii) and sugar pine (Pinus lambertiana). Plant Cell Rep. 4: 177-179

Hansen J (1987) Stock plant lighting and adventitious root formation. Hort Science 22: 746-749

Hasnain S \& Cheliak W (1986) Tissue culture in forestry: economic and genetic potential. For. Chronicle (August 1986): 219-225

Horgan K \& Holland L (1989) Rooting of micropropagated shoots from mature radiata pine. Can. J. For. Res. 19: 1309-1315

Huetteman CA \& Preece JE (1993) Thidiazuron; a potent cytokinin for woody plant tissue culture. Plant Cell Tiss. Org. Cult. 33: 105-119

Kretzschmar U (1993) Improvement of larch micropropagation by induced short shoot elongation in vitro. Silvae Genet. 42: 163169

Kretzschmar U \& Ewald D (1994) Vegetative propagation of 140 year- old Larix decidua trees by different in vitro techniques. J. Plant Physiol 144: 627-630

Laliberté S \& Lalonde M (1988) Sustained caulogenesis in callus cultures of Larix $\times$ eurolepis initiated from short shoot buds of a 12-year-old tree. Amer. J. Bot. 75: 767-777

Legendre L \& Legendre P (1984) Ecologie Numérique 1. Le Traitement Multiple des Données Ecologiques. Masson, Paris \& les Presses de l'Université du Québec (260p)

Mac An t-Saoir S, O'Brien J \& Selby C(1991) Apparent rejuvenation of mature Sitka spruce in culture. Acta Hort. 289: 337-338

Mapes MO, Young PM \& Zaerr JB (1981) Multiplication in vitro du Douglas (Pseudotsuga menziesii) par induction précoce d'un bourgeonnement adventif et axillaire. In: Colloque International sur la Culture in vitro des Essences Forestières, IUFRO S2 015 , Fontainebleau, AFOCEL (pp 109-114)

McKeand SE (1985) Expression of mature characteristics by tissue culture plantlets derived from embryos of loblolly pine. J. Amer. Soc. Hort. Sci. 110: 619-623
Mohammed GH \& Vidaver WE (1990) The influence of acclimatization treatment and plantlet morphology on early greenhouseperformance of tissue-cultured Douglas fir [Pseudotsuga menziesii (Mirb.) Franco]. Plant Cell Tiss. Org. Cult. 21: 111-117

Mohammed GH \& Vidaver WE (1991 ) Early development of douglas-fir plantlets following transfer to the greenhouse. Plant Science 76: 259-265

Mohammed GH, Patel KR \& Vidaver WE (1989) The control of adventitious root production in tissue-cultured Douglas-fir. Can. J. For. Res. 19: 1322-1329

Monteuuis O \& Dumas E (1992) Morphological features as indicators of maturity in acclimatized Pinus pinaster from different in vitro origins. Can. J. For. Res. 22: 1417-1421

Murashige T \& Skoog F (1962) A revised medium for rapid growth and bioassays with tobacco tissue cultures. Physiol Plant 15: 473-497

New Brunswick Forest Research Advisory Committee (1986) 1986 Larch workshop. Forestry Canada, Fredericton, N.B.

Pâques LE (1989) A critical review of larch hybridization and its incidence on breeding strategies. Ann Sci For 46: 141-153

Pierik RLM (1990) Rejuvenation and micropropagation. IAPTC Newsletter 62: 11-21

Pullman GS \& Timmis R (1992) Establishment of juvenile-like shoot cultures and plantlets from 4-16 year-old Douglas-fir (Pseudotsuga menziesii (Mirb.) Franco) trees. Plant Cell Tiss. Org. Cult. 29: 187-198

Richard S, Gauthier S \& Laliberté S (1995) Isozyme assessment of the genetic stability of micropropagated hybrid larch, Larix $\times$ eurolepis Henry. Can. J. For. Res. 25: 1103-1112

Ritchie GA \& Long AJ (1986) Field performance of micropropagated Douglas fir. New Zeal. J. For. Sci, 16: 343-356

Schenk RV \& Hildebrandt AC (1972) Medium and techniques for induction and growth of monocotyledonous and dicotyledonous plant cell cultures. Can. J. Bot. 50: 199-204

Statistical Analysis System (1987) SAS Proc GLM, SAS Institute Inc.

Steiner AA \& Van Winden H (1970) Recipe for ferric salts of ethylenediaminetetraacetic acid. Plant Physiol. 46: 862-863

Wyman J, Brassard N, Flipo D \& Laliberte S (1992) Ploidy level stability of callus tissue, axillary and adventitious shoots of Larix $\times$ eurolepis Henry regenerated in vitro. Plant Sci. 85: 189-196 